\title{
KAJIAN KARAKTERISTIK FISIK, MEKANIK DAN AERODINAMIK DAUN TEH HASIL PETIKAN YANG TELAH DILAYUKAN
}

\section{STUDY ON PHYSICAL, MECHANICAL, AND AERODYNAMIC CHARACTERISTICS OF WITHERED TEA LEAF}

\author{
Agus Sutejo $^{1 凶}$, Sutrisno Suro Mardjan ${ }^{1}$, Wawan Hermawan ${ }^{1}$, Desrial ${ }^{1}$ \\ ${ }^{1}$ Departemen Teknik Mesin dan Biosistem, Fakultas Teknologi Pertanian, Institut Pertanian Bogor \\ ${ }^{\square}$ Komunikasi Penulis, email: dtm_cyber@yahoo.com \\ DOI:http://dx.doi.org/10.23960/jtep-lv9i3.171-183 \\ Naskah ini diterima pada 3 Juni 2020, revisi pada 18 Agustus 2020, \\ disetujui untuk dipublikasikan pada 21 Agustus 2020
}

\begin{abstract}
The design of the wilted tea stalk and leaf separation system aims to improve the quality of the tea produced especially by separating the tea leaves and stalks at the beginning of the process. Stages that are needed to be done include designing a chopper machine that is capable of chopping tea stems and leaves to a certain size and designing stem and leaf separation system with the pneumatic principle with suction. In this study, physical, mechanical and aerodynamic characteristics of tea leaves were measured. The result showed that force to release a leaf is in the range of values between 12.24-16.17 N smaller than the need for the cutting force of the stem and leaves and the greatest difference in force is achieved at a water content between 55 and $58 \%$ bb (leaves) and 66$68 \% \mathrm{bb}$ (stalk). The leaf terminal velocity is $<3 \mathrm{~m} \mathrm{~s}$ - 1 while the tea terminal velocity is $>9 \mathrm{~m} \mathrm{~s}-1$. Tea leafyield value is very important as a reference in testing the performance of tea and tea leaf separator machines where the average leafyield is $77.33 \%$ and the average stem yield is $22.67 \%$.
\end{abstract}

Keywords: characteristic of tea leaves, engineering, separation of tea leaves, withering of tea leaves

\begin{abstract}
ABSTRAK
Perancangan sistem pemisahan batang dan daun teh layu bertujuan untuk meningkatkan kualitas teh yang dihasilkan terutama dengan memisahkan daun dan batang teh pada awal proses. Tahapan yang perlu dilakukan antara lain merancang mesin perajang yang mampu merajang batang dan daun teh dengan ukuran tertentu serta merancang sistem pemisahan batang dan daun dengan prinsip pneumatik dengan penghisapan. Pada penelitian ini dilakukan pengukuran karakteristik fisik, mekanik dan aerodinamis daun teh. Hasil penelitian menunjukkan bahwa gaya untuk melepaskan daun berada pada kisaran nilai antara 12,24 N -16,17 N lebih kecil dari kebutuhan gaya potong batang dan daun dan perbedaan gaya terbesar dicapai pada kadar air antara 55\%-58\% bb (daun) dan 66\%-68\% bb (batang). Kecepatan terminal daun <3 m s-1 sedangkan kecepatan terminal teh $>9 \mathrm{~m} \mathrm{~s}-1$. Nilai rendemen daun teh sangat penting sebagai acuan dalam pengujian kinerja mesin pemisah daun teh dan teh dimana rerata rendemen daun sebesar $77,33 \%$ dan rerata rendemen batang sebesar 22,67\%.
\end{abstract}

Kata Kunci: karakteristik daun teh, pelayuan daun teh, pemisahan daun teh, rancang bangun

\section{PENDAHULUAN}

Perancangan sistem pemisahan tangkai dan daun teh layu bertujuan untuk meningkatkan mutu teh yang dihasilkan khususnya dengan cara memisahkan daun dan tangkai teh pada awal proses. Tahapan yang perlu dilakukan antara lain merancang mesin pencacah yang mampu mencacah batang dan daun teh menjadi ukuran tertentu dan merancang sistem pemisahan batang dan daunnya dengan prinsip pneumatik dengan hisapan. Namun sebelum merancang mesin pemisah tangkai dan daun teh diperlukan berbagai informasi terkait karakteristik fisik, mekanik dan aerodinamik dari bahan yaitu pucuk teh. Kajian karakteristik fisik, mekanik dan aerodinamik petikan teh bertujuan mendapatkan data-data sebagai dasar dalam perancangan mesin pemisah tangkai dan daun teh layu untuk peningkatan efisiensi dalam proses pengolahan teh yang telah ada. Hal ini sangat penting karena data dan informasi terkait 
teh khususnya karakteristik mekanik dan aerodinamik teh lokal dari Indonesia masih belum ada.

Pengukuran karakteristik fisik, mekanik dan aerodinamik dilakukan dengan mengacu pada standar dan metode yang telah dilakukan oleh penelitian-penelitian sebelumnya (Sutejo, et al, 2018a, Sutejo etal, 2018b). Beberapa hasil kajian mengenai pemisahaan biji-bijian dari pengotornya dijadikan referensi untuk pengukuran karakteristik tangkai dan daun teh berdasarkan sifat aerodinamis bahan. Oleh karena itu pada penelitian ini dilakukan pengukuran dan kajian sifat-sifat fisik, mekanik dan aerodinamik teh yang bertujuan untuk mendapatkan informasi karakteristik teh dari daun dan tangkai teh untuk keperluan perancangan mesin pemisah tangkai dan daun teh.

\section{BAHAN DAN METODA}

Penelitian ini dilakukan di Laboratorium Manufaktur Departemen Teknik Mesin dan Biosistem yang dimulai pada bulan Januari 2016 sampai dengan November 2018. Kegiatan penelitian dimulai dengan melakukan analisis hasil petikan, analisis sifat fisik dan mekanik tangkai dan daun teh untuk perancangan mesin pencacah serta analisis sifat aerodinamis tangkai dan daun teh untuk perancangan mesin pemisah tangkai dan daun. Diagram alir penelitian penelitian dapat dilihat pada Gambar 1.

\subsection{Analisis Sifat Fisik, Mekanik dan Aerodinamik Tangkai dan Daun Teh}

Berdasarkan bentuk fisik dari tangkai dan daun teh diperlukan pengecilan ukuran untuk mempermudah proses pemisahan dari tangkai dan daun teh secara mekanik. Pengecilan ukuran

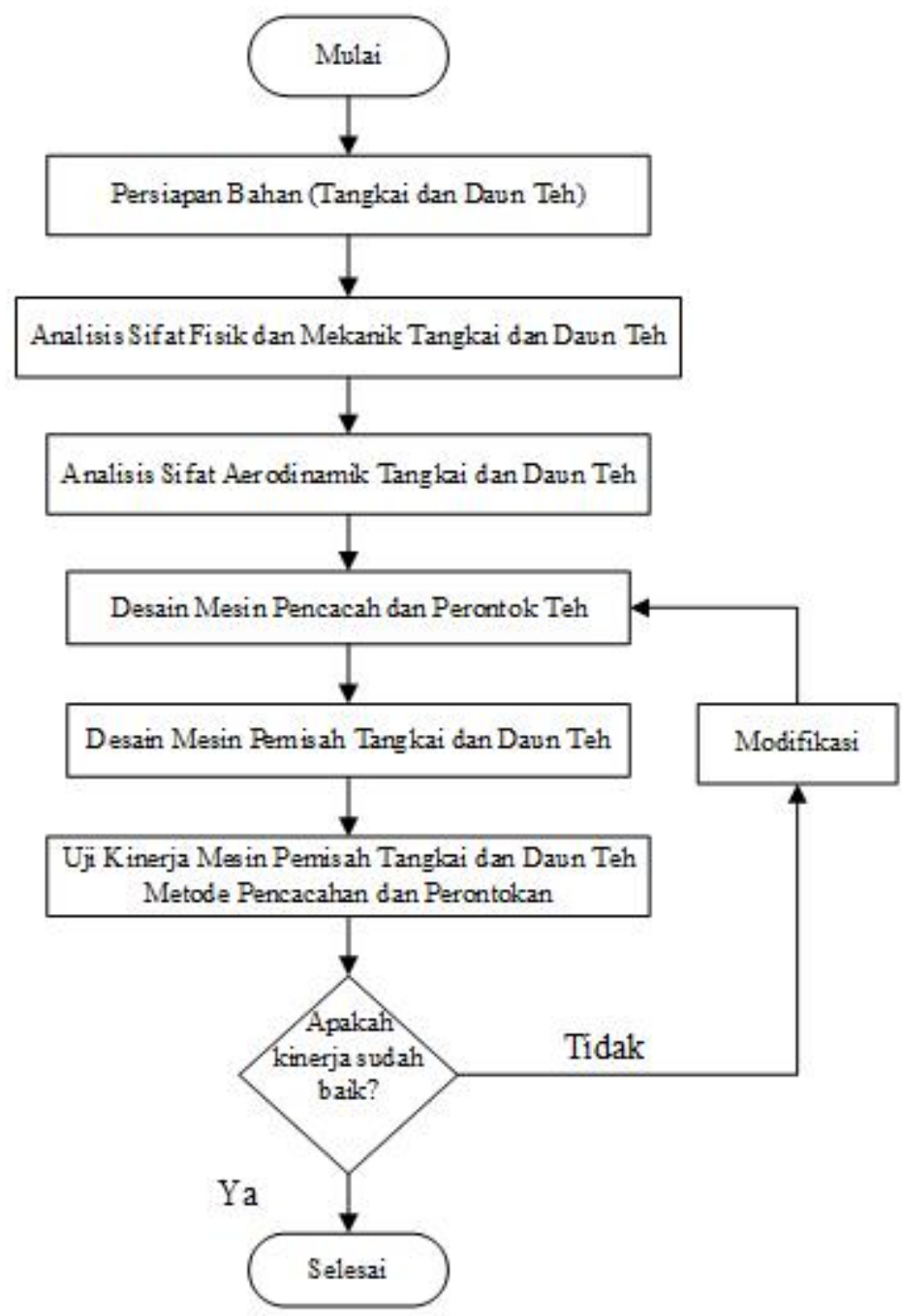

Gambar 1. Diagram Alir Tahapan Penelitian 
tangkai dan daun teh dapat dilakukan dengan beberapa mekanisme namun demikian pada proses pengecilan ukuran kulit tangkai tidak boleh terkelupas karena bila kulit tangkai terkelupas akan menyisakan kayu dan kayu tersebut bila tercampur dengan daun teh dan akan menjadi pengotor yang akan menurunkan mutu teh. Untuk itu mekanisme yang dipilih pada proses pengecilan ukuran ada dua yaitu melalui mekanisme pencacahan menggunakan pisau pemotong dan mekanisme perontokan dengan silinder perontok. Untuk merancang mesin pencacah, perontok dan pemisah tangkai dan daun diperlukan analisis sifat fisik, mekanik dan aerodinamik dari tangkai dan daun teh sehingga dihasilkan mesin yang sesuai dengan kriteria yang ditetapkan. Bahan yang digunakan pada analisis sifat fisik, mekanik dan aerodinamik adalah pucuk teh Camellia sinensis varietas Asammica yang langsung dipetik dengan cara digunting langsung dari pohonnya. Bahan teh diperoleh dari perkebunan teh PT. Perkebunan Nusantara VIII, Cianten, Bogor, Jawa Barat. Teh yang dipetik dimasukkan ke dalam karung dan langsung dibawa ke lab uji di Departemen Teknik Mesin dan Biosistem IPB pada hari yang sama. Teh yang belum diuji disimpan di dalam lemari pendingin agar kesegarannya dapat bertahan. Teh yang diukur ada yang dalam bentuk segar (dimensi petikan teh, jumlah helai daun dan sudut curah) dan juga ada yang dilayukan terlebih dahulu sesuai jenis parameter yang diukur.

\subsection{Pengukuran Dimensi Tangkai Petikan Teh}

Dimensi tangkai petikan teh terdiri dari diameter tangkai (d) dan tinggi petikan teh (t). Pengukuran dimensi dari tangkai teh bertujuan untuk menentukan kapasitas hopper mesin pencacah dan mesin perontok tangkai dan daun teh. Petikan teh diperoleh dengan cara digunting dari pohonnya kemudian diambil sampelnya sebanyak 50 pucuk. Tinggi petikan teh diukur menggunakan penggaris dengan skala ketelitian $1 \mathrm{~mm}$ sementara diameter tangkai diukur menggunakan jangka sorong dengan ketelitian $0.05 \mathrm{~mm}$. Prosedur pengukuran tinggi dan diameter tangkai dapat dilihat pada Gambar 2 .

\subsection{Pengukuran Jumlah Helai Daun Petikan Teh}

Analisis jumlah helai daun pada petikan teh bertujuan menentukan jarak antar pisau pemotong supaya tangkai dan daun mudah dipisahkan. Sampel petikan teh yang diukur diambil dari persediaan pucuk teh hasil pengambilan dari perkebunan. Jumlah helai daun dihitung secara manual dan jumlah sampel yang diukur adalah 30 sampel.

\subsection{Sudut Curah (Angle of Repose) Petikan Teh}

Penentuan sudut curah (angle of repose) dilakukan untuk menentukan kemiringan penampung (hopper) dan kemiringan mesin pengayak tangkai dan daun teh. Alat yang digunakan plat stainless steel (SS), ember dan meteran. Perhitungan sudut curah dilakukan berdasarkan Guo et al. (2013) dengan sketsa pengukuran seperti pada Gambar 3. Plat SS digunakan sebagai alas tempat jatuh pucuk teh kemudian diambil sampel pucuk teh dan dimasukkan ke dalam wadah ember. Sampel petikan teh dijatuhkan pada plat SS sehingga membentuk suatu tumpukan dengan diameter dan tinggi tertentu. Kemudian diameter curah diukur dengan meteran, begitu juga tinggi curah dari tumpukan pucuk teh. Sudut curah dihitung menggunakan Persamaan 1.

$$
\phi_{R}=\tan ^{-1}\left(\frac{B C}{A C}\right)
$$

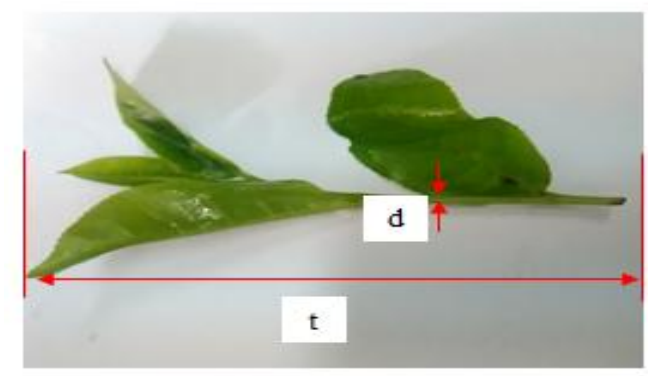

Gambar 2. Prosedur Pengukuran Tinggi dan Diameter Petikan Teh 
Dengan, $\Phi_{F}$ adalah sudut curah $\left(^{\circ}\right), B C$ adalah tinggi tumpukan teh (m), dan $A C$ adalah radius tumpukan teh $(\mathrm{m})$.

\subsection{Pengukuran Gaya Potong Tangkai dan Daun Teh}

Pengukuran besarnya gaya tahanan potong tangkai dan daun teh bertujuan untuk mengukur berapa kebutuhan gaya untuk dapat memotong tangkai dan daun teh sehingga dapat diketahui kebutuhan tenaga dan jenis mata pisau untuk memotong tangkai dan daun teh. Pada saat pemotongan akan terjadi perubahan gaya pada pisau pemotong sebagai akibat gaya reaksi yang diberikan tangkai dan daun teh terhadap pisau pemotong. Alat yang digunakan pada pengukuran tahanan potong adalah Universal Testing Machine (UTM) Amsler tipe 120, sample holder dan dua jenis mata pisau yaitu tumpul dan tajam (sudut ketajaman $20^{\circ}$ ) yang dipasang pada UTM. Posisi bahan (tangkai dan daun) saat pengujian dapat dilihat pada Gambar 4a dan 4b. Bahan diletakkan pada sample holder kemudian UTM dioperasikan dengan kecepatan konstan. Nilai gaya maksimal dicatat ketika tangkai atau daun teh terpotong. Pengujian dilakukan pada 5 tingkat kadar air yang berbeda. Proses yang dilakukan untuk merubah kadar airnya adalah dengan memanaskan pucuk teh menggunakan hair dryer yang memiliki daya 1400 W. Posisi bahan saat dipanaskan adalah tegak lurus dengan mulut hair dryer dengan jarak $20 \mathrm{~cm}$. Variasi kadar air diperoleh dari lamanya pemanasan yaitu $0,20,35,45$ dan 60 menit. Uji gaya potong setiap perlakuan dilakukan sebanyak 30 kali ulangan.

\subsection{Pengukuran Gaya Melepas Daun dari Tangkai}

Gaya melepas daun dari tangkai diperlukan untuk merancang besarnya gaya optimum untuk merontokkan daun sehingga dapat terlepas dari tangkai. Alat yang digunakan pada pengukuran gaya melepas daun adalah Universal Testing Machine (UTM) Amsler tipe 120, sampel holder dan mata pisau tumpul yang terbuat dari stainless steel. Sama seperti pengukuran gaya potong, pengoperasian UTM dilakukan pada kecepatan konstan, nilai gaya maksimal dicatat ketika daun teh terlepas (putus) dari tangkainya. Posisi pengukuran gaya melepas daun disajikan pada Gambar 4c. Pengujian dilakukan pada 5 tingkat kadar air sama seperti pengukuran gaya potong tangkai dan daun. Uji pelepasan daun pada setiap perlakuan dilakukan sebanyak 30 kali ulangan.

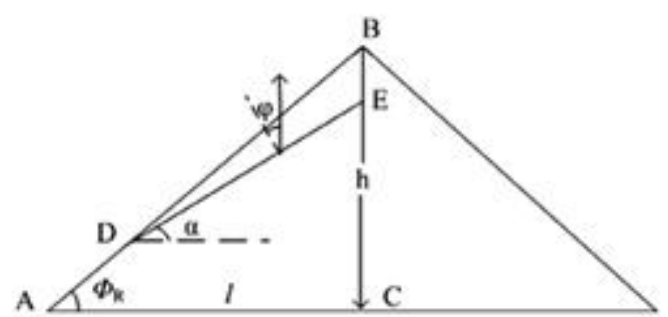

Gambar 3. Sketsa Pengukuran Parameter Untuk Perhitungan Sudut Curah (Guo et al. 2013)

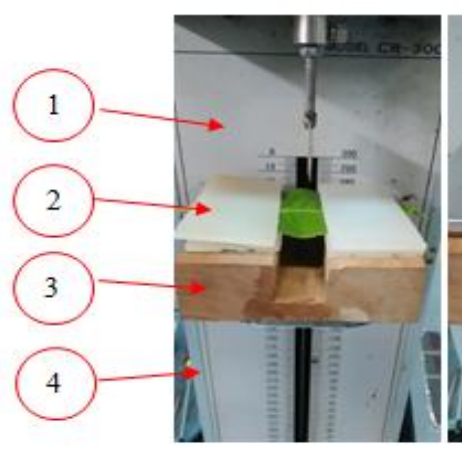

(a)

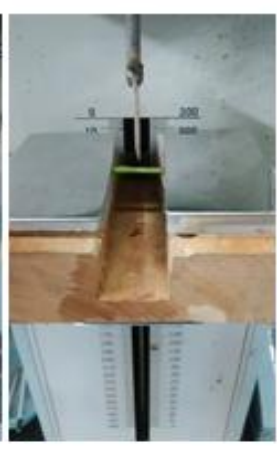

(b)

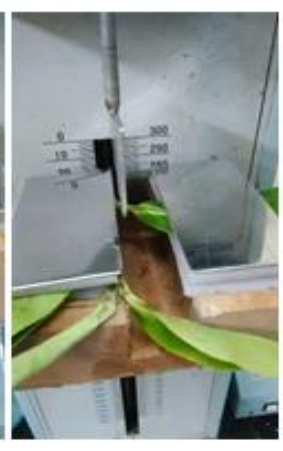

(c)
Keterangan :

1. Mata pisau

2. Sampel teh (tangkai dan daun)

3. Sample holder

4. Skala

Gambar 4. Posisi Penempatan Sampel Pada UTM: (a) Sampel Daun Teh, (b) Sampel Tangkai Teh, dan (c) Sampel Pucuk Teh Untuk Uji Melepas Daun 


\subsection{Pengukuran Terminal Velocity Daun dan Tangkai Teh}

Terminal velocity dapat dijadikan acuan untuk penentuan kecepatan angin yang efektif untuk pemisahan tangkai dan daun, dimana dipilih sedikit di bawah terminal velocity tangkai agar tangkai tidak terhisap, dan sejauh mungkin dari terminal velocity daun agar daun terhisap sehingga terpisah antara tangkai dan daun. Ilustrasi pengukuran terminal velocity dapat dilihat pada Gambar 5. Menurut Glenn Research Center (GRC) dari NASA, suatu benda akan mencapat terminal velocity apabila kecepatan pada saat $\mathrm{Fd}=\mathrm{Fg}$ dimana $\mathrm{Fg}$ adalah gaya berat benda $\left(\mathrm{m}^{*} \mathrm{~g}\right)$ dan $\mathrm{Fd}$ adalah gaya angkat (drag force) dalam satuan Newton. Sehingga persamaan untuk menghitung terminal velocity adalah sebagai berikut (NASA, 2019):

$$
\begin{aligned}
& F_{d}=\frac{c d * \rho * v^{2} * A}{2} \\
& \frac{c d * \rho * v^{2} * A}{2}=m^{*} g \\
& v=\sqrt{\frac{2 *\left(m^{*} g\right)}{c d * \rho * A}}
\end{aligned}
$$

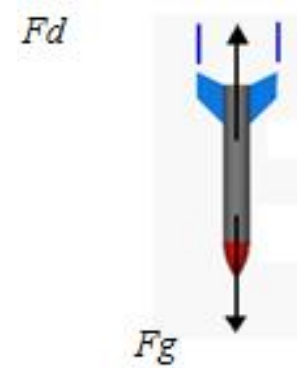

Gambar 5. Ilustrasi Pengukuran Terminal Velocity (NASA, 2019)

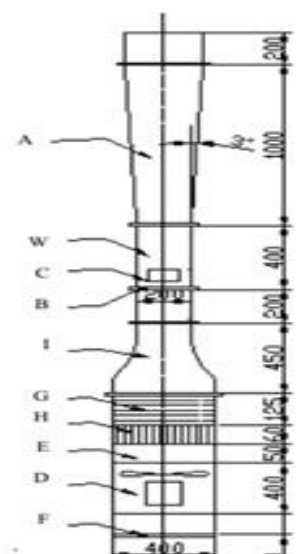

Gambar 6. Vertical Wind Tunnel (A) Diffuser, (B) Wire Net, (C) Lid Hatch, (D) Axial Fan, (E) Flexible Section, (F) Diaphragm, (G) Mesh Screens, (H) Honeycomb, (I) Nozzle, (W) Support section (Khoshtaghaza dan Mehdizadeh, 2006)
Dengan, $C_{d}$ adalah koefisien drag, $\rho$ adalah massa jenis udara $\left(\mathrm{kg} \mathrm{m}^{-3}\right), v$ adalah terminal velocity $\left(\mathrm{m} \mathrm{s}^{-1}\right)$, $\mathrm{m}$ adalah massa benda $(\mathrm{kg})$, dan A adalah luas proyeksi benda $\left(\mathrm{m}^{2}\right)$.

Karena parameter gravitasi $(g)$, koefisien drag $(C d)$ dan massa jenis $(\rho)$ nilainya tetap maka yang paling mempengaruhi perubahan terminal velocity adalah massa $(m)$ dan luas proyeksi $(A)$. Oleh karena itu parameter yang diukur pada saat pengukuran adalah massa $(m)$, luas projeksi $(A)$ dan terminal velocity $(v)$, kemudian memasukkan nilai $m$ dan $A$ ke dalam Persamaan 5 sebagai suatu nilai fungsi $f(m, A)$.

$$
f=\sqrt{\frac{m}{A}}
$$

Pengukuran terminal velocity dilakukan untuk mengetahui besarnya kecepatan udara yang diperlukan agar daun dan tangkai teh dapat melayang di udara. Data tersebut digunakan untuk keperluan perancangan blower penghisap yang tujuannya dapat menghisap daun saja tanpa ada tangkai yang terhisap atau sedikit mungkin yang terhisap. Alat yang digunakan adalah $\mathrm{Hot}$ wire anemometer merk Krisbow dan vertical wind tunnel untuk menerbangkan bahan 
(Gambar 7a). Vertical wind tunnel dibuat berdasarkan desain oleh Khoshtaghaza dan Mehdizadeh (2006) untuk mengukur terminal velocity yang dapat dilihat pada Gambar 6. Prosedur pengukurannya dimulai dari dimasukkannya sampel ke dalam kamar apung sebagai percobaan untuk menentukan kecepatan putar kipas yang sesuai. Mesin kipas yang terhubung dengan ruang apung dinyalakan dan diatur kecepatan putarnya dengan cara mengubah nilai potensiometernya hingga sampel dapat melayang. Kemudian dilakukan kalibrasi kecepatan udara pada kamar apung pada tiap titik di dalam ruang apung (dengan cara memasukkan batang anemometer ke dalam setiap lubang di sisi kiri ruang apung) (Gambar $7 b)$.

Setelah kalibrasi, pengukuran terminal velocity dilakukan. Satu sampel teh (daun atau batang) dimasukkan ke dalam ruang apung kemudian dilihat posisi sampel tersebut sejajar dengan lubang nomor berapa ketika sampel melayang dengan stabil. Pengukuran dilakukan pada 3 variasi kadar air. Perbedaan kadar airnya diperoleh dari perlakuan lama pemanasan yang berbeda yaitu 0,15 dan 30 menit menggunakan alat pemanas udara. Pengukuran terminal velocity dilakukan pada 3 bagian pucuk teh yaitu daun, tangkai serta tangkai yang ada daunnya (masing-masing bagian terdiri dari 5 ukuran yang berbeda seperti pada Gambar 8).

Pada Gambar 7a dapat dilihat bahwa diameter ruang apung semakin atas semakin besar yang mengakibatkan kecepatan udara semakin kecil. Itulah sebabnya dilakukan kalibrasi terlebih dahulu sebelum pengukuran. Kalibrasi dilakukan dengan mengukur kecepatan udara pada tiap titik di dalam ruang apung. Pada Gambar $7 \mathrm{~b}$ dapat dilihat bahwa di sebelah kiri alat terdapat banyak lubang yang digunakan untuk mengukur kecepatan udara pada beberapa titik. Parameter dari bahan diukur terlebih dahulu yaitu massa dan luas proyeksi teh sebelum diukur terminal velocity-nya sehingga dapat diperoleh hubungan atau keterkaitan antara nilai terminal velocity dengan fungsi akar dari massa dibagi luas proyeksi teh $(f(m, A))$ sehingga di kemudian hari nilai terminal velocity dapat diduga atau

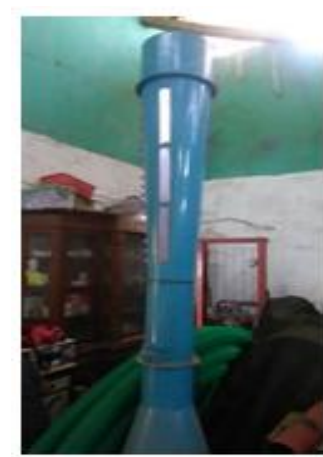

(a)

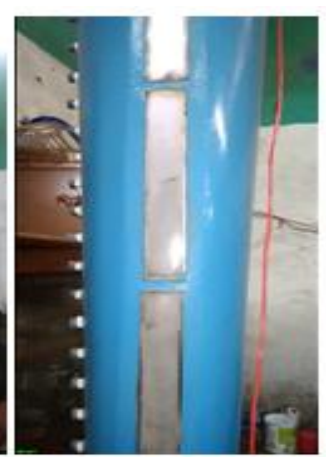

(b)

Gambar 7. Vertical Wind Tunnel Untuk Pengukuran Terminal Velocity Bahan (a) Tampak Keseluruhan Alat dan (b) Bagian Pada Ruang Apung Untuk Pengamatan
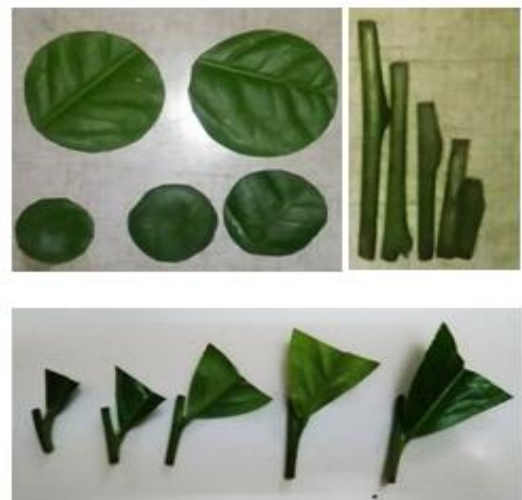

Gambar 8. Bagian-Bagian Pucuk Teh Untuk Perngukuran Terminal Velocity 
diprediksi dari parameter massa dan luas proyeksinya saja.

\subsection{Pengukuran Kadar Air dan Massa Jenis Daun dan Tangkai Teh}

Pengukuran massa jenis dilakukan secara terpisah antara daun dan tangkai karena daun dan tangkai teh memiliki karakteristik yang berbeda sehingga perlu dilakukan pengukuran secara terpisah agar data yang diperoleh akurat. Pengukuran dilakukan pada 5 kondisi kadar air yang berbeda agar diketahui ada atau tidaknya pengaruh kadar air terhadap massa jenis. Perbedaan kadar air diperoleh dari perbedaan lamanya waktu pelayuan (pemanasan) pucuk teh yaitu mulai dari $0,15,30,45$ hingga 60 menit Kadar air daun dan tangkai teh masing-masing diukur dengan menggunakan metode pengukuran kadar air bahan kayu secara langsung menggunakan oven seperti yang dilakukan oleh Hartley dan Marchant (1995). Bahan ditimbang massanya terlebih dahulu sebelum dimasukkan ke dalam oven, kemudian bahan ditimbang kembali setelah disimpan di dalam oven selama 24 jam pada suhu $105^{\circ}-110^{\circ}$. Rumus untuk menghitung kadar air dapat dilihat pada Persamaan 6.

$$
K_{a}=\frac{m_{a w}-m_{a k}}{m_{a w}} * 100 \%
$$

Dengan, $K_{a}$ adalah kadar air bahan (\%bb), $m_{a w}$ adalah massa awal bahan (g), dan $m_{a k}$ adalah massa akhir bahan (g).

Pengukuran massa jenis daun dan tangkai dilakukan dengan menghitung volume dari daun dan tangkai serta mengukur (menimbang) massanya. Adapun untuk volume daun diperoleh dengan memotong daun menjadi bentuk segi empat kemudian mengukur panjang, lebar dan tebalnya sehingga diperoleh nilai volumenya. Sementara volume tangkai diperoleh dari pengukuran diameter dan panjang tangkai. Nilai massa jenis diperoleh dengan membagi massa ( $\mathrm{g}$ ) dengan volume bahan $\left(\mathrm{cm}^{3}\right)$.

\subsection{Pengukuran Rendemen Daun dan Tangkai Teh}

Pengukuran rendemen daun dan tangkai teh dilakukan untuk mengetahui besarnya persentase bobot daun dan tangkai teh terhadap bobot pucuk teh keseluruhan. Pengukuran dilakukan dengan cara mengambil petikan teh secara acak secukupnya dari bahan baku percobaan. Kemudian daun dan tangkai teh dipisahkan dengan memotongnya menggunakan gunting. Daun dan tangkai teh yang sudah terpisah ditimbang masing-masing menggunakan timbangan. Pengukuran rendemen dilakukan sebayak tiga kali ulangan. Rendemen tangkai dan daun dihitung menggunakan Persamaan 7 dan 8.

$$
\begin{aligned}
& R_{t}=\frac{B_{t}}{B_{t d}} * 100 \% \\
& R_{d}=\frac{B_{d}}{B_{t d}} * 100 \%
\end{aligned}
$$

Dengan, $\mathrm{R}_{\mathrm{t}}$ adalah rendemen potongan tangkai (\%), $\mathrm{R}_{\mathrm{d}}$ adalah rendemen potongan daun (\%), $\mathrm{B}_{t}$ adalah berat potongan tangkai $(\mathrm{kg}), \mathrm{B}_{\mathrm{d}}$ adalah berat potongan daun $(\mathrm{kg})$, dan $\mathrm{B}_{\mathrm{td}}$ adalah berat tangkai dan daun teh awal $(\mathrm{kg})$.

\subsection{Pengolahan Data Hasil Pengukuran}

Data hasil pengukuran diolah dengan melihat nilai mean (rata - rata) dan SD (standar deviasi) nya dari suatu distribusi normal dan pengambilan kesimpulan dengan persentil. Distribusi normal ditandai dengan adanya nilai mean (rata-rata) dan SD (standar deviasi). Sedangkan persentil adalah suatu nilai yang menyatakan bahwa persentase tertentu dari sekelompok yang dimensinya sama dengan atau lebih dari nilai tersebut. Misalnya: 95\% populasi adalah sama dengan atau lebih rendah dari 95 persentil, $5 \%$ dari populasi berada sama dengan atau lebih rendah dari 5 percentil. Besarnya nilai persentil dapat ditentukan dari tabel probabilitas distribusi normal seperti pada Gambar 9.

\section{HASIL DAN PEMBAHASAN}

\subsection{Dimensi Tangkai Petikan Teh}

Hasil pengukuran dimensi tangkai teh yaitu diameter tangkai dan panjang tangkai petikan teh telah dilakukan pada 50 sampel pucuk teh yang diambil secara acak. Informasi yang diperoleh dari pengukuran adalah berupa nilai rata-rata, standar deviasi dan persentil 95. Data hasil pengukuran dapat dilihat pada Tabel 1. Informasi yang dapat digunakan untuk perancangan mesin pencacah adalah data persentil 95 karena posisi celah antar pisau 
pencacah harus mampu dilewati oleh 95\% tangkai teh sehingga tangkai tidak akan terkikis atau terkoyak oleh pisau. Berdasarkan pengukuran diketahui bahwa panjang tangkai teh cukup panjang dengan nilai persentil 95 sebesar $21.55 \mathrm{~cm}$. Hal ini terjadi karena proses pemanenan dilakukan menggunakan gunting dan prosesnya dalam sekali menggunting dapat terpotong $>10$ tangkai sehingga ada beberapa tangkai yang terpotong lebih panjang dari seharusnya untuk mengantisipasi tidak terpotongnya pucuk yang rendah. Namun demikian dalam hal rata-rata sudah cukup baik yaitu $11.11 \mathrm{~cm}$. Data dimensi tangkai petikan teh dapat dijadikan acuan ukuran celah pisau pemotong agar tangkai dapat lolos tanpa terkelupas kulitnya dan juga ukuran lubang pemasukan pucuk teh agar proses pemasukan bahan mudah dan lancar.

\subsection{Jumlah Helai Daun pada Petikan Teh}

Berdasarkan perhitungan jumlah helai daun teh secara manual didapatkan hasil bahwa jumlah helai rata-rata adalah 5 daun teh dengan nilai pada persentil 95 sebesar 6.45 daun. Dalam hal ratarata hal ini sudah sesuai dengan kriteria pucuk teh $(p+4)$ artinya 1 helai pucuk, 2 helai pucuk muda dan 2 helai pucuk tua sehingga sudah cukup sesuai untuk menghasilkan teh dengan kualitas yang sangat baik. Adapun nilai persentil 95 sebesar 6.45 helai. Hal ini berkorelasi dengan panjang petikan teh sebagaimana Tabel 1 yang mana ada beberapa tangkai yang terpotong lebih panjang dari seharusnya untuk mengantisipasi tidak terpotongnya pucuk yang rendah. Semakin panjang tangkai yang terpotong ini tentu akan menambah jumlah helai daun yang ikut terambil sehingga bisa mencapai 6-7 daun terambil. Data jumlah helai daun diperlukan untuk perancangan hopper khususnya kapasitas.

\subsection{Angle of Repose Petikan Teh}

Bahan yang diukur sudut curahnya adalah pucuk teh segar dengan kadar air sekitar 70-75\%. Hasil perhitungan sudut curah (angle of repose) disajikan pada Tabel 2. Pengukuran dilakukan sebanyak 3 kali ulangan dan diperoleh nilai angle of repose rata-rata sebesar $40.48^{\circ}$ dan nilai pada persentil 95 adalah $44.57^{\circ}$. Angle of repose diperlukan untuk menentukan sudut kemiringan corong pengumpan (hopper) pada saat perancangan mesin pencacah pucuk teh. Berdasarkan nilai persentil tersebut maka perancangan kemiringan hopper harus dibuat $>$ $44.57^{\circ}$ agar pengumpanan pucuk teh dapat berjalan dengan lancar.

\subsection{Kadar Air dan Massa Jenis Daun dan Tangkai Teh}

Hasil pengukuran menunjukkan bahwa peningkatan lamanya waktu pelayuan (pemanasan) pada pucuk teh telah menurunkan kadar air tangkai dan daun teh. Namun penurunan kadar air daun dan tangkai tidak sama. Kadar air tangkai cenderung menurun lebih kecil dibandingkan dengan daun teh. Hal ini dipengaruhi oleh faktor bentuk, ketebalan dan luas permukaan yang berbeda dari daun dan

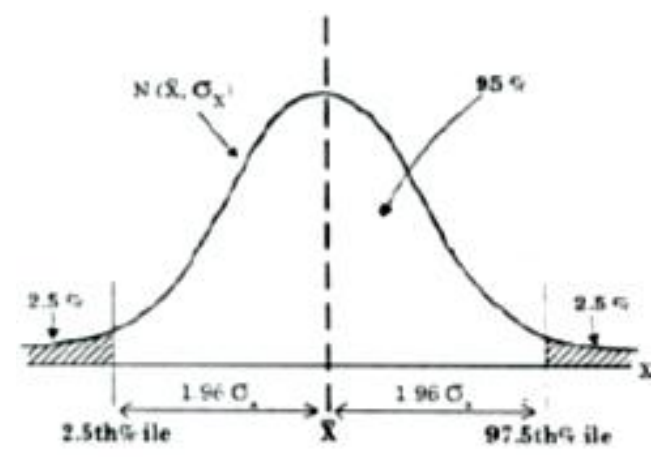

\begin{tabular}{|l|l|l|l|}
\hline Perventil & Perhitungan & Persentil & Perhitungan \\
\hline Ke-1 & $\bar{x}-2.325 \sigma_{2}$ & Ke-90 & $\bar{f}+1.280 \sigma_{4}$ \\
Ke-2.5 & $\bar{x}-1.960 \sigma_{2}$ & Ke-95 & $\bar{x}+1.645 \sigma_{3}$ \\
Ke-5 & $\bar{x}-1.645 \sigma_{4}$ & Ke-97.5 & $\bar{x}+1.960 \sigma_{4}$ \\
Ke-10 & $\bar{x}-1.280 \sigma_{4}$ & Ke-99 & $\bar{x}+2.325 \sigma_{3}$ \\
Ke-50 & $\bar{x}$ & & \\
\hline
\end{tabular}

Gambar 9. Distribusi Normal dan Perhitungan Persentil

Tabel 1. Hasil Pengukuran Dimensi Tangkai Petikan Teh

\begin{tabular}{lccc}
\hline Parameter & Persentil 95 & Rata-rata & Standar deviasi \\
\hline Diameter $(\mathrm{mm})$ & 3.05 & 2.58 & 0.33 \\
Panjang tangkai $(\mathrm{cm})$ & 21.55 & 11.11 & 5.55 \\
\hline
\end{tabular}


Tabel 2. Hasil Perhitungan Angle Of Repose Petikan Teh

\begin{tabular}{cccc}
\hline Parameter & Persentil 95 & Rata-rata & Standar Deviasi \\
\hline Sudut curah $\left({ }^{\circ}\right)$ & 44.57 & 40.48 & 4.63 \\
\hline
\end{tabular}

Tabel 3. Hasil Pengukuran Kadar Air dan Massa Jenis Daun dan Tangkai Teh

\begin{tabular}{ccccc}
\hline $\begin{array}{c}\text { Waktu } \\
\text { Pelayuan } \\
\text { (menit) }\end{array}$ & $\begin{array}{c}\text { Kadar Air } \\
\text { Daun (\%bb) }\end{array}$ & $\begin{array}{c}\text { Kadar Air } \\
\text { Tangkai (\%bb) }\end{array}$ & $\begin{array}{c}\text { Massa Jenis } \\
\text { Daun (g/cm } \mathbf{3} \text { ) }\end{array}$ & $\begin{array}{c}\text { Massa Jenis Batang } \\
\text { (g/cm } \mathbf{3} \text { ) }\end{array}$ \\
\hline 0 & 70.15 & 74.31 & 0.70 & 1.22 \\
15 & 66.01 & 68.67 & 0.62 & 1.14 \\
30 & 57.17 & 68.33 & 0.53 & 1.09 \\
35 & 50.27 & 64.39 & 0.51 & 1.08 \\
60 & 46.97 & 62.91 & 0.51 & 1.02 \\
\hline
\end{tabular}

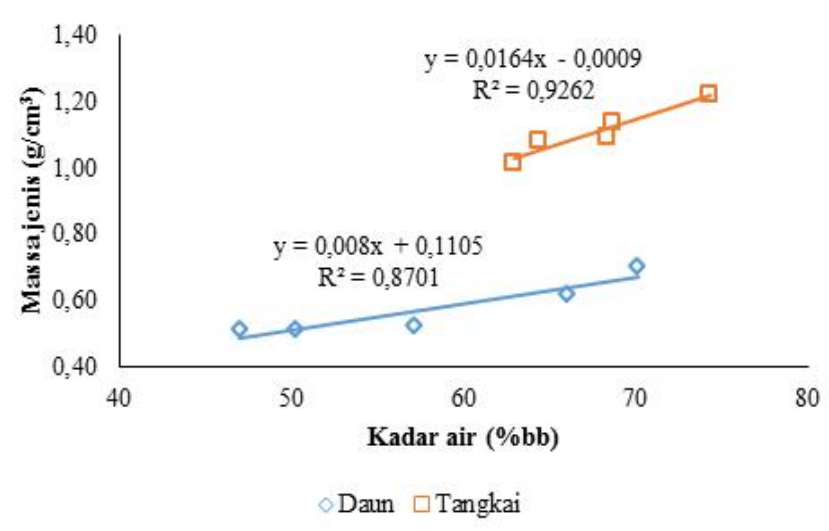

Gambar 10. Grafik Hasil Pengukuran Kadar Air dan Massa Jenis

tangkai yang mana daun memiliki luas permukaan yang lebih luas dan ketebalan yang tipis sehingga air lebih mudah menguap sehingga penurunan kadar air lebih cepat. Data hasil pengukuran dapat dilihat pada Tabel 3 dan grafiknya dapat dilihat pada Gambar 10. Data kadar air sangat penting karena pengujian beberapa parameter teh dilakukan pada beberapa tingkat kadar air seperti terminal velocity dan gaya potong tangkai dan daun.

Hasil pengukuran menunjukkan bahwa ada pengaruh perubahan kadar air terhadap massa jenis daun dan tangkai teh yaitu pada daun nilai $\mathrm{R}^{2}$-nya adalah 0.926 dan pada tangkai sebesar 0.870 . Massa jenis daun lebih kecil dibandingkan dengan tangkai yang mana massa jenis daun berkisar antara $0.51-0.70 \mathrm{~g} / \mathrm{cm}^{3}$ dan tangkai berkisar antara $1.02-1.22 \mathrm{~g} / \mathrm{cm}^{3}$. Hal yang menarik dari pengujian ini adalah terdapat perbedaan laju penurunan kadar air antara daun dan bahan. Berdasarkan Gambar 11 diketahui bahwa penurunan kadar air daun teh lebih cepat dibanding penurunan kadar air tangkai yang mana dengan waktu pelayuan 60 menit dapat menurunkan kadar air daun sebesar $23.18 \%$ bb sedangkan tangkai hanya $11.4 \%$ bb artinya waktu proses pengeringan/pelayuan dapat berjalan 2 kali lebih cepat (dengan syarat hanya daun yang diproses). Ini menjadi keuntungan tersendiri apabila pengolahan teh sudah berupa daunnya saja (tangkai diproses secara terpisah). Oleh karena itu diperlukan pemisahan antara daun dan tangkai pada awal proses pengolahan teh.

\subsection{Gaya Potong dan Gaya Melepas Daun} Hasil pengukuran gaya potong (daun dan tangkai) serta gaya untuk melepas daun dari tangkai dapat dilihat pada Tabel 4. Pengukuran telah dilakukan pada 5 tingkat kadar air yang berbeda. Nilai kadar air berubah seiring dengan meningkatnya lama pemanasan. Grafik hubungan kadar air dengan gaya potong dan gaya melepas daun disajikan pada Gambar 12. 


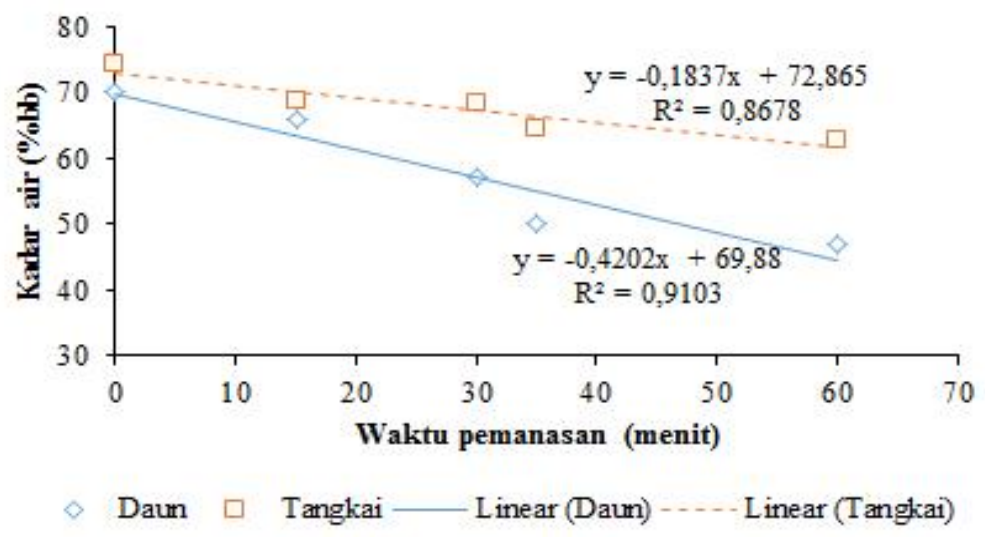

Gambar 11. Grafik Perubahan Kadar Air Daun dan Tangkai Teh Terhadap Waktu

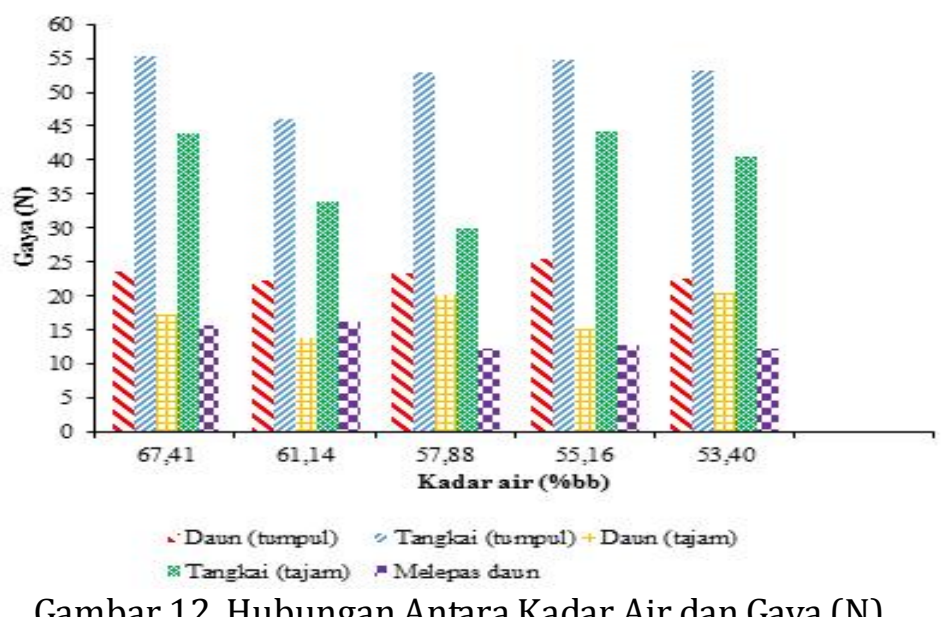

Gambar 12. Hubungan Antara Kadar Air dan Gaya (N)

Berdasarkan Gambar 12 dapat diketahui bahwa gaya untuk melepas daun menunjukkan nilai yang selalu lebih rendah dibanding gaya untuk memotong daun dan tangkai yang menggunakan pisau tumpul pada semua tingkat kadar air. Selisih gaya antara gaya untuk memotong daun dan gaya melepas daun berada pada kisaran 6.28-12.65 N. Sementara selisih antara gaya untuk memotong tangkai dan gaya melepas daun berada pada kisaran 29.92-41.79 N. Sehingga dapat disimpulkan bahwa bagian pada sambungan daun dan tangkai merupakan titik yang paling rapuh (memiliki gaya yang paling rendah). Kebutuhan gaya untuk melepas daun lebih kecil dari pada gaya untuk memotong daun dan tangkai pada kelima tingkat kadar air. Kebutuhan gaya untuk melepas daun berada pada kisaran nilai antara 12.24-16.17 N. Sementara itu nilai selisih gaya yang paling besar dicapai pada kadar air antara 55-58 \%bb (daun) dan 66-68 \%bb (tangkai). Dengan demikian peluang melepaskan daun secara utuh dari tangkai dapat dilakukan pada kisaran kadar air 55-58 \%bb (daun) yang mana pukulan pisau tumpul menghasilkan selisih paling jauh antara titik pada tangkai, daun dan sambungan daun dengan perbandingan berturutturut $54.59 \mathrm{~N}: 25.44 \mathrm{~N}$ : $12.82 \mathrm{~N}$. Artinya untuk perancangan silinder perontok, pemukul harus dapat memukul dengan besar gaya $>12.82 \mathrm{~N}$ dan $<25.44 \mathrm{~N}$ sehingga diharapkan daun dapat terlepas dari tangkai tanpa merusak bagian daun dan tangkai.

\subsection{Terminal Velocity Daun dan Tangkai Teh} Hasil pengukuran terminal velocity telah dilakukan pada 3 tingkat kadar air yang berbeda. Hal ini dilakukan untuk mengetahui ada tidaknya pengaruh kadar air terhadap terminal velocity. Secara umum hasil pengukuran dari ketiga perlakuan kadar air menunjukkan bahwa terdapat hubungan antara terminal velocity dengan akar dari massa (g) dibagi luas proyeksi $\left(\mathrm{cm}^{2}\right)$ bahan. Grafik hubungan antara terminal velocity dengan fungsi dari massa dan luas proyeksi bahan disajikan pada Gambar 13.

Berdasarkan Gambar 13 dapat diketahui bahwa dari ketiga perlakuan kadar air menunjukkan 
Tabel 4. Hasil Pengukuran Gaya Potong Dan Gaya Melepas Daun Teh

\begin{tabular}{|c|c|c|c|c|c|c|}
\hline \multirow[t]{2}{*}{ KA Daun (\%) } & \multirow{2}{*}{$\begin{array}{c}\text { KA } \\
\text { Tangkai } \\
\text { (\%) }\end{array}$} & \multicolumn{2}{|c|}{$\begin{array}{c}\text { Gaya Potong Pisau } \\
\text { Tumpul Persentil } \\
95(\mathrm{~N}) \\
\end{array}$} & \multicolumn{2}{|c|}{$\begin{array}{c}\text { Gaya Potong Pisau } \\
\text { Tajam Persentil } \\
95(\mathrm{~N}) \\
\end{array}$} & \multirow{2}{*}{$\begin{array}{c}\text { Gaya Melepas } \\
\text { Daun } \\
\text { Persentil } 95 \\
\text { (N) }\end{array}$} \\
\hline & & Daun & Tangkai & Daun & Tangkai & \\
\hline 67.41 & 73.90 & 23.50 & 55.31 & 17.16 & 43.81 & 15.75 \\
\hline 61.14 & 65.53 & 22.40 & 46.12 & 13.89 & 33.93 & 16.17 \\
\hline 57.88 & 68.25 & 23.24 & 52.78 & 20.10 & 29.94 & 12.24 \\
\hline 55.16 & 66.57 & 25.44 & 54.59 & 15.26 & 44.24 & 12.82 \\
\hline 53.40 & 65.79 & 22.44 & 53.22 & 20.36 & 40.50 & 12.31 \\
\hline
\end{tabular}

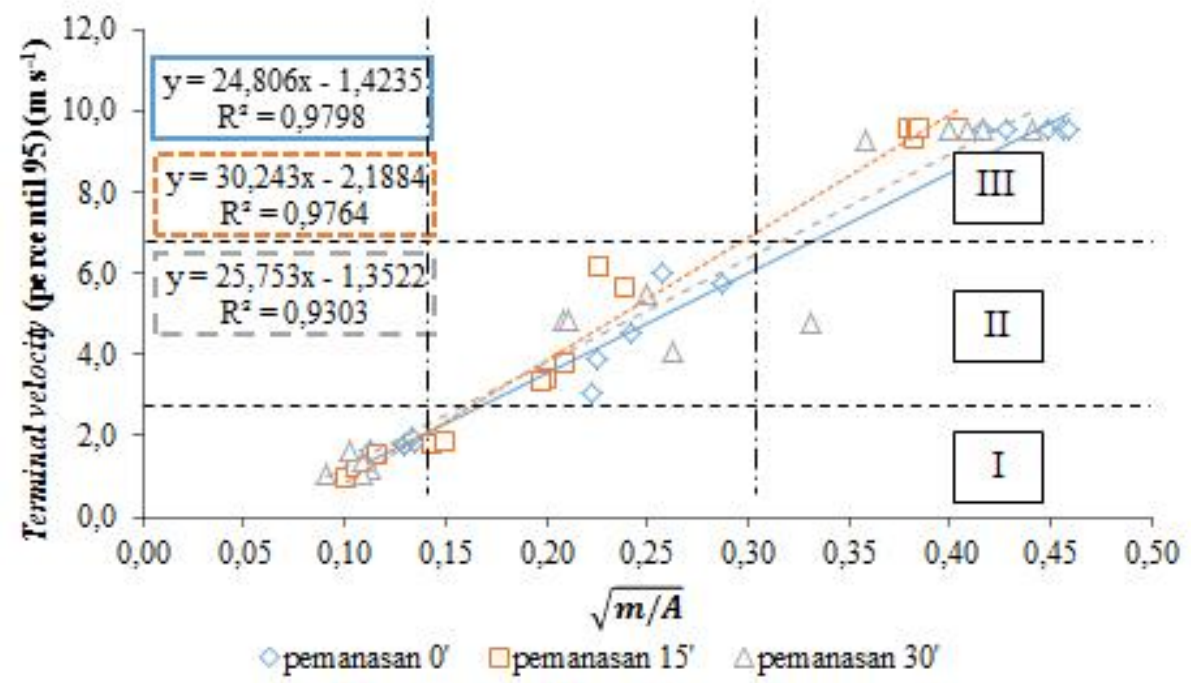

Gambar 13. Hubungan Antara Terminal Velocity Dengan Fungsi Massa dan Luas Proyeksi Bahan Pada 3 Kadar Air Daun Yang Berbeda Berbeda (70.15 \%bb, 66.01 \%bb dan 57.17 \%bb)

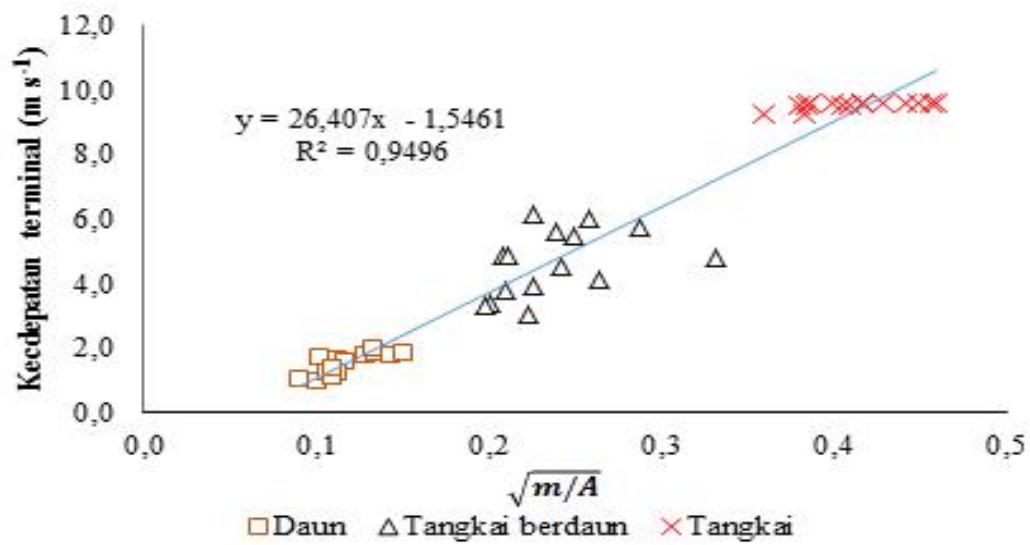

Gambar 14. Hubungan Antara Terminal Velocity Dengan Fungsi Massa dan Luas Proyeksi Bahan (Kadar Air Gabungan)

bahwa terdapat korelasi yang tinggi antara terminal velocity dengan akar dari massa dibagi luas proyeksi yang ditunjukkan oleh besarnya nilai $\mathrm{R}^{2}$ dari ketiganya yaitu bernilai di atas $93 \%$. Fungsi massa dan luas proyeksinya berupa akar persamaan dari massa dibagi luas proyeksi. Sementara itu dari ketiga perlakuan kadar air menunjukkan tidak ada perbedaan yang nyata antara ketiganya karena garis kurva kadar air paling rendah (pemanasan 30') berada diantara garis kurva kadar air tertinggi dan kadar air tertinggi kedua sehingga tidak ada korelasinya. Informasi lain pada Gambar 14 yaitu baris grafik (I) adalah wilayah terminal velocity daun, baris 
Tabel 5. Hasil Pengukuran Rendemen Daun dan Tangkai Teh

\begin{tabular}{lcc}
\hline Parameter & Rata-Rata & Standar Deviasi \\
\hline Massa daun (g) & 120.34 & 9.07 \\
Massa tangkai (g) & 35.26 & 2.83 \\
Total massa (g) & 155.60 & 11.30 \\
Rendemen daun (\%) & 77.33 & 1.00 \\
Rendemen tangkai (\%) & 22.67 & 1.00 \\
\hline
\end{tabular}

grafik (II) adalah wilayah terminal velocity tangkai yang ada daun serta baris grafik (III) adalah wilayah terminal velocity tangkai saja. Berdasarkan hasil tersebut dapat diketahui bahwa terminal velocity daun merupakan yang paling kecil yaitu $<3 \mathrm{~m} \mathrm{~s}^{-1}$ sementara terminal velocity tangkai teh mencapai nilai $>9 \mathrm{~m} \mathrm{~s}^{-1}$ yang artinya terdapat perbedaan yang sangat besar antara nilai keduanya sehingga mekanisme pemisahan berdasarkan karakteristik terminal velocity sangat sesuai untuk digunakan pada mesin pemisah tangkai dan daun teh. Selain itu dapat disimpulkan juga bahwa semakin besar nilai fungsi $f(m, A)$ maka semakin tinggi terminal velocity dari bahan/material teh. Kemudian Gambar 14 adalah grafik yang menunjukkan nilai gabungan semua data dari ketiga kadar air. Berdasarkan grafik tersebut diketahui bahwa pengaruh kadar air dapat diabaikan karena keseluruhan data menunjukkan tren yang positif dengan nilai $\mathrm{R}^{2}$ sebesar 0.9496 dan persamaan yang diperoleh yaitu $\mathrm{y}=26.407 \mathrm{x}-1.5461$, dengan $\mathrm{y}$ adalah terminal velocity $\left(\mathrm{m} \mathrm{s}^{-1}\right)$ dan $\mathrm{x}$ adalah fungsi akar $\left(\mathrm{m} \mathrm{A}^{-1}\right)$. Dengan demikian diperoleh perbedaan yang cukup jauh antara terminal velocity daun dan tangkai yang memungkinkan daun dan tangkai dapat dipisah secara pneumatik dengan cara dihisap dengan $v$ hisap $=3 \mathrm{~ms}^{-1}$ (sedikit di atas terminal velocity daun) sehingga tangkai dan tangkai berdaun tidak terhisap. Nilai $v$ tersebut harus mampu dihasilkan oleh blower khususnya pada bagian mulut hisapnya.

\subsection{Rendemen Daun dan Tangkai Teh}

Berdasarkan hasil pengukuran rendemen daun dan tangkai teh, diperoleh besarnya rendemen daun rata-rata adalah $77.33 \%$ dan rendemen tangkai rata-rata adalah $22.67 \%$ artinya bobot daun mencapai lebih dari 3 kali lipat bobot tangkai. Data hasil pengukuran disajikan pada Tabel 5.
Hasil pengukuran rendemen daun teh ini sangat penting untuk digunakan sebagai acuan dalam pengujian kinerja mesin pemisah daun dan tangkai teh yang dibuat dan juga untuk mengetahui tingkat keberhasilan pemisahannya. Selain itu dapat diperhitungkan juga berdasarkan informasi rendemen daun maka kapasitas input bahan pucuk teh dapat ditingkatkan apabila bagian yang diproses hanya daun saja. Jika pada awalnya sebuah proses hanya mampu mengolah 1 ton material teh (tanpa dipisah tangkai dan daun) maka setelah disisipkan mesin pemisah yang dirancang diharapkan pucuk teh yang dapat diproses meningkat menjadi 1.29 ton (rendemen daun $77.33 \%$ ) yang mana akan menghasilkan daun teh sebesar 1 ton untuk diolah ke tahap berikutnya.

\section{KESIMPULAN}

Pisau tumpul merupakan jenis pisau yang paling baik untuk diterapkan pada mesin perontok teh karena menghasilkan selisih gaya yang paling besar antara gaya potong dan gaya melepas daun. Gaya potong daun dan gaya rontok dapat digunakan sebagai acuan yang memungkinkan daun teh dirontokkan tanpa merusak daun teh sehingga dapat dijadikan alternatif daun dirontokkan kemudian dipisah. Kebutuhan gaya untuk melepas daun berada pada kisaran nilai antara 12.24-16.17 $\mathrm{N}$ lebih kecil dibanding kebutuhan gaya potong tangkai dan daun serta nilai selisih gaya yang paling besar dicapai pada kadar air antara 55-58 \%bb (daun) dan 66-68 $\%$ bb (tangkai). Mekanisme pemisahan berdasarkan karakteristik terminal velocity sangat sesuai untuk digunakan pada mesin pemisah tangkai dan daun teh. Terminal velocity daun berada pada nilai $<3 \mathrm{~m} \mathrm{~s}^{-1}$ sementara terminal velocity tangkai teh berada pada nilai $>$ $9 \mathrm{~m} \mathrm{~s}^{-1}$. Semakin besar nilai fungsi $f(m, A)$ maka 
semakin tinggi terminal velocity dari bahan/ material teh. Nilai rendemen daun teh sangat penting untuk digunakan sebagai acuan dalam pengujian kinerja mesin pemisah daun dan tangkai teh yang mana rendemen daun rata-rata adalah $77.33 \%$ dan rendemen tangkai rata-rata adalah $22.67 \%$.

\section{DAFTAR PUSTAKA}

Hartley J dan Marchant J. 1995. Methods of determining the moisture content of wood. Research Division, State Forests of New South Wales. Technical Paper No. 41.

Guo Z, Chen X, Liu H, Guo Q, Guo X, Lu H. 2013. Theoretical and experimental investigation on angle of repose of biomass-coal blends. Fuel (2013). Available at: http://dx.doi.org/10.1016/ j.fuel.2013.07.098.

Khoshtaghaza M dan Mehdizadeh R. 2006. Aerodynamic Properties of Wheat Kernel and Straw Materials. Agricultural Engineering International: the CIGR Ejournal. Manuscript FP 05 007.Vol. VIII.

[NASA] National Aeronautics and Space Administration. Terminal Velocity (gravity and drag) dalam https:// www.grc.nasa.gov/www/k-12/airplane/ termv.html. [Diakses tanggal 21 Januari 2019].

Sutejo A, Mardjan, S.S, Hermawan, W., Desrial. 2018a. Kinerja Mesin Pemisah Potongan Tangkai dan Daun Teh. Jurnal Teknik Pertanian Lampung Vol.7, No. 3: 160-167.

Sutejo A, Mardjan, S.S, Hermawan, W., Desrial. 2018b. Design and Performance of TeaShootsChopper: Optimization of StemsAnd Leaves Separation. INTERNATIONAL Journal of Scientific \&Technology Research. Vol.7, Issue 10. 